\title{
The Fourth Industrial Revolution (Industry 4.0): A Social Innovation Perspective
}

\author{
Rabeh Morrar, Husam Arman, and Saeed Mousa
}

\author{
"The scale, scope and complexity of how technological") \\ revolution influence our behavior and way of living \\ will be unlike anything humankind has experienced.
}

\author{
Klaus Schwab \\ Engineer and Economist; Founder and Executive \\ Chairman of the World Economic Forum
}

\begin{abstract}
The rapid pace of technological developments played a key role in the previous industrial revolutions. However, the fourth industrial revolution (Industry 4.0) and its embedded technology diffusion progress is expected to grow exponentially in terms of technical change and socioeconomic impact. Therefore, coping with such transformation require a holistic approach that encompasses innovative and sustainable system solutions and not just technological ones. In this article, we propose a framework that can facilitate the interaction between technological and social innovation to continuously come up with proactive, and hence timely, sustainable strategies. These strategies can leverage economic rewards, enrich society at large, and protect the environment. The new forthcoming opportunities that will be generated through the next industrial wave are gigantic at all levels. However, the readiness for such revolutionary conversion require coupling the forces of technological innovation and social innovation under the sustainability umbrella.
\end{abstract}

\section{Introduction}

Every industrial revolution brought with it benefits and challenges to the socioeconomic status of the countries that have engaged in such transformation. For instance, Great Britain led the first industrial revolution with the invention of the commercial steam engine, which revolutionized communication and transportation and led to many other industrial developments. In the second industrial revolution, the United States was primarily in the lead, with the telephone revolutionizing communication this time. In the third industrial revolution, the Internet was the key factor and succeeded because it was conceived as a public infrastructure technology rather a proprietary technology (Carr, 2003). The Internet has transformed the world economic landscape, and this transformation is expected to continue with the Internet of things (IoT). Rifkin (2014) confirms this trend in his concept of zero marginal cost, which emphasizes connectivity in his anticipation of a collaborative economy that will replace the capital system in its current form - with the IoT as the main driver. The rapid progress of smart cities is also paving the way to a more collaborative world (Kanter \& Litow, 2009).

All these industrial revolutions have resulted in economic growth, increased productivity, and advanced welfare in the countries that managed to reap most of its positive impact, including from high-quality goods and services. However, the wealth distribution within the developed countries who led the industrial revolution was not equitable, certainly not at the global level, where inequality has become one of the key challenges along with climate change and other sustainability issues. The rapid depletion of Earth's resources at the expense of the future of the society and environment has created an epic global challenge. Concepts such as sustainability and social innovation have surfaced and have rapidly attracted global attention as potential resolutions. The United Nations global initiative towards sustainable development goals (SDGs) has sent a strong message committing to inclusive social and economic development (UN, 2014). Innovative efforts in using, for 


\section{The Fourth Industrial Revolution (Industry 4.0): A Social Innovation Perspective}

\section{Rabeh Morrar, Husam Arman, and Saeed Mousa}

instance, the sustainable livelihood approach to link socioeconomic and environmental issues are also endeavours (Brocklesby \& Fisher, 2003).

Industry 4.0 is not an exception to the previous eras of industries, but it is expected to bring immense benefits and many challenges. However, the main challenge that most stakeholders are concerned with is the cybersecurity risk given that the IoT is the backbone of Industry 4.0, which has the potential to enlarge the level risk exponentially from where we are today. Moreover, the rate of the technological development in Industry 4.0 is exponential and, therefore, anticipating the challenges and even the benefits is much more difficult than what the world experienced in the previous industrial revolutions. This increased difficulty is due to the high convergence of technologies that could complement or compete with different possible diffusion scenarios that may result in more frequent breakthroughs that are difficult to forecast. Hence, the policy and regulation due to the speed of progress may lack a remedy for any unexpected consequences or developments if the policy resolutions remain non-global and reactive.

Social challenges are mainly the immense risk of cybercrime due to increased connectivity, and job losses due to the automation of large segments of operations in many industries as part of Industry 4.0. Although new opportunities may appear for high-skill categories, as argued by Drucker (2014), but will the volume of these new jobs meet the supply of labour? In addition to automation, the rapid development and recent successes of artificial intelligence in business domains have raised the bar. IBM has already made leaf frog development of system solutions in different obvious fields, and Watson of IBM is a striking example (Waters, 2016).

Therefore, technological and business-driven innovative solutions are not going to be enough. Innovation in its broadest sense is the key solution, in particular social innovation. The same drive to innovate technologies to increase productivity can also be utilized to improve welfare and societal needs of the world population.

In this article, we use an exploratory approach to discuss how we can tackle Industry 4.0 from a not only economic view but also from social and environmental perspectives. In other words, we discuss Industry 4.0 in the context of social innovation. We seek to bridge some of the theoretical gaps about how Industry 4.0 can be discussed from both technological and social in- novation perspectives. And, to facilitate this bridging of gaps, we propose a simple framework to address the above issues using a holistic perspective that aims to ignite an innovative and constructive conversation rather than specific technical solutions.

\section{Literature Review and Theoretical Background}

The world is changing very fast thanks to the technological revolution that greatly influences our way of living and the behaviour of both individuals and organizations. Industry 4.0 (also known as Fourth Industrial Revolution) manifests itself in the way data changes, technologies are automated and digitized, and what we now call the Internet of things (IoT).

In this section, we review the relevant literature and discuss the theoretical background of Industry 4.0, social innovation, and the interaction between Industry 4.0 and innovation in general. Our intention is to explore the Industry 4.0 concept, including its economic, social, and environmental interactions.

\section{What is Industry 4.0 ?}

Industry 4.0 is related to what is called the "smart factory" (Dutton, 2014). In a smart factory, a virtual copy of the physical world and decentralized decision making can be developed (Buhr, 2015). Also, physical systems can cooperate and communicate with each other and with humans in real time, all enabled by the IoT and related services.

The debate about Industry 4.0 and its global impact is growing rapidly due to intense discussions about digitization, the Internet of things, and smart knowledge and systems (Friess \& Ibanez, 2014; Vermesan et al., 2014). The debate is driven by uncertainty about the best way to exploit the fast pace of technological innovation to improve various aspects of human life .

The concept of Industry 4.0 has its origins in Germany and has been recognized by other leading industrial nations, although it is known as "Connected Enterprise" in the United States and the "Fourth Industrial Revolution" in the United Kingdom. In any case, Industry 4.0 is built on three preceding technological transformations: steam power, which was the transformative force of the nineteenth century; electricity, which transformed much of the twentieth, and the era of the computer beginning of 1970s (Cordes \& Stacey, 2017). We 


\title{
The Fourth Industrial Revolution (Industry 4.0): A Social Innovation Perspective
}

\author{
Rabeh Morrar, Husam Arman, and Saeed Mousa
}

expect that the impact of Industry 4.0 will be more profound, irreversible, and much more rapid than the previous three generations. The high growth in the demand of technologies (mainly information and communication technologies) by industrial firms can fuel the future of Industry 4.0 and may result in positive spillover effects to different areas.

The term "Industry 4.0" was originated in 2011 at the Hanover Fair in Germany as a strategy to mitigate the increasing competition from overseas and to differentiate German and European Union industries from other international markets (Pascall, 2017). Also, the German government sought to use intelligent monitoring in production processes in order to aid decision making and machine maintenance to reduce costs and increase the competitiveness of German industries. In order to understand what is meant by Industry 4.0, PwC (2017) proposed a framework, which also was adopted by the Flemish Government. The idea of the framework arose by asking leading companies to determine their priorities among a group of concepts. Smart systems, humans in Industry 4.0, smart production, and people skills were identified as the highest priorities.

Schmitt (2015) confirmed five reasons why Industry 4.0 is important and is seen to be revolutionary in the era of information technology and open market operations. First, Industry 4.0 mitigates the burden of current challenges for manufactures in order to make the companies more flexible and responsive to business trends. Among these challenges are the ones of increasing market volatility, shorter product lifecycles, higher product complexity, and global supply chains. For example, smart items will bring stronger integration of top floor and shop floor and thus more intelligence and flexibility to production. Second, Industry 4.0 enables the transformation of modern economies to become more innovative and hence increase productivity. It is expected that the use of modern technologies such as digital chains, smart systems, and the industrial Internet will speed up innovations as new business models can be implemented much faster. Third, it highlights the role of consumer as a co-producer and puts them in the centre of all activities. The customization of products is the most important activity in the product value chain, and digitization will facilitate crowdsourcing, which in turn will lead to a faster design process. Industry 4.0 puts humans in the centre of production. Workers will be assigned where help is needed, hence there will be higher demands in the workforce for skills in managing complex projects, yet more flexible work will also be- come available. Finally, we argue that it will enable sustainable prosperity through the use of modern technologies to find solutions to the challenges related to energy, resources, environment, and social and economic impacts. Innovative solutions can reduce energy consumption, help companies to sustain their business with existing and new business models, and use new technologies to produce all over the world (even at high-cost locations) close to the markets utilizing the domestic workforce skills.

Acatech (2014) described Industry 4.0 as the IoT: data and services that will change future production, logistics, and work processes. This means that the evolution of the IoT has gone beyond Internet-connected applications in recent years with the integration of different technologies such as machine learning, embedded systems, and wireless connection. The European Research Cluster on the Internet of Things (IERC) (Vermesan et al., 2009) stated that the IoT is " an integrated part of Future Internet and could be defined as a dynamic global network infrastructure with self-configuring capabilities based on standard and interoperable communication protocols where physical and virtual 'things' have identities, physical attributes, and virtual personalities and use intelligent interfaces, and are seamlessly integrated into the information network." IERC added that "things" in the IoT "are expected to become active participants in business, information and social processes where they are enabled to interact and communicate among themselves and with the environment by exchanging data and information 'sensed' about the environment, while reacting autonomously to the 'real/physical world' events and influencing it by running processes that trigger actions and create services with or without direct human intervention". Vermesan and colleagues (2014) confirmed that the main goal of the IoT is to "enable things to be connected anytime, anyplace, with anything and anyone ideally using any path/network and any service".

\section{What is social innovation?}

Social innovations are known as new practices used to tackle social challenges; they have a positive influence on individuals, society, and organizations (Hahn \& Andor, 2013). Social innovations have also been defined as new models, services, and products that simultaneously meet social needs (Marolt et al., 2015). They can be expressed by one or a combination of the following: law, regulation, behaviour, service, business model, perception, organization, or technology (Abott, 2014). Based on these broad definitions, many innovations 


\section{The Fourth Industrial Revolution (Industry 4.0): A Social Innovation Perspective}

Rabeh Morrar, Husam Arman, and Saeed Mousa

can be classified as social innovations, including selfhelp health groups and self-build housing; Wikipedia and the Open University; complementary microcredit and consumer cooperatives; charity shops and the air trade movement; zero carbon housing schemes; and community wind farms (Mulgan et al., 2007).

The concept of social innovation denotes the processes and factors that lead to a sustained positive transformation to the network society (Mulgan, 2006; Phills et al., 2008). It is defined as an innovative solution to the increasing challenges that face society - one that is more effective, more efficient, more sustainable, or more equitable than existing practices (Phills et al., 2008). Phills and co-authors (2008) confirm that social innovation should express both the newness and improved responses to societal needs. Society's appreciation of the resulting benefits of social innovation exceeds the traditional model, which usually benefits the innovators themselves. Many known innovations can be classified as social innovations, for example, sustainable solutions to environment problems, health insurance, new learning models, and transportation facilities. Social innovation flourished recently as a promising mechanism to tackle the inefficiency of the existing policies and models targeting the most pressing global issues such as chronic diseases, climate changes, and inequality (Murray et al., 2010).

\section{Industry 4.0 and innovation}

Industry 4.0 is highly connected with innovation. In the last decade, innovation added further ingredients to the mix - mobile, cloud, social media, and big data - which together might build a perfect symbiosis, create new concept for the industrialization process, and shift the market into new era of competition and differentiation of products (Geiger \& Sá, 2013). Industry 4.0 represents a shift toward an innovation-based economy with knowledge, data, and the IoT as central concepts. This will affect the current structure, markets, and business processes of the industrial age and pave the way to a new age of digitization, "smarter" networking of production systems, and interlinked business processes.

In the new industrial revolution, traditional competitive factors such as market share, economies of scale, and access to resources are now linked or joined with other factors such as innovation, intellectual property rights, smart technology, and access to knowledge (Geiger \& Sá, 2013). Furthermore, the role of the consumer is changing in the production process; the availability of relevant information for both consumers and business units allows for more interactive relationships between them so that the consumer needs can be better fulfilled. The consumer's role in the production process is vital: they are now a co-producer. Meanwhile, radical process innovation is associated with the technological revolution; tailored production series will replace industrial or mass-manufacturing facilities (Buhr, 2017).

Also, customers have become more outcome oriented (Geiger \& Sá, 2013), and the "make-for-me" approach represents a new business model. These trends have contributed to the emerging concept of mass customization in manufacturing (Da Silveira et al., 2001), where many firms started to introduce new marketing interfaces and manufacturing processes to meet the customized customers requirements who are willing to pay for customized features of the goods and services. For example, consumers now choose their education approach and define exactly what they need from courses and knowledge rather than passing through the traditional and formal teaching approach, which leads to incremental and radical innovation in the education system that consider project-based and research-based learning and interactive learning as the top priority. Companies are expected to modify the business models for their innovation and insert flexible value chains to increase responsiveness to the changes in consumer behaviour. A smart factory with smart production systems will cope with such demand while maintaining highquality products and services.

\section{Discussion}

Most of the recent literature about the Fourth Industrial Revolution focuses on the technological innovation nature of Industry 4.0. There is concern about whether the fast growth in technological development and digitization is leaving a positive influence on the individuals and society (Luppicini, 2012). Thus, when considering how technological progress can be exploited to solve society problems, we must also view technological innovations through a social perspective.

Industry 4.0 represented by the high growth in technology-enabled platforms has disrupted the existing industry structures and created new ways of consuming goods through the combination of demand and supply. It also organizes how people work and consume, it changes the nature of assets, and it affects how data is obtained and manipulated. Moreover, it lowers the barriers for people and businesses to invest and create wealth, which in turn alters the surrounding personal and professional environments (Schwab, 2015). 


\section{The Fourth Industrial Revolution (Industry 4.0): A Social Innovation Perspective}

\section{Rabeh Morrar, Husam Arman, and Saeed Mousa}

Since the 2016 World Economic Forum, which set Industry 4.0 on its agenda as a global issue, this new buzzword has been associated with rapid technological breakthroughs that lead to the transformations in all aspects of our socioeconomic lives. In this view, one of the key questions is how countries can create the conditions for the fourth industrial revolution and associated emerging technologies to bring new opportunities and benefits to the people and society, to help remedy the damage to the society that the last three revolutions caused, as well as enabling a sustainable fourth industrial revolution.

This new economic paradigm makes the Internet (and data) a way to create value for people and societies and not only serve as a communication channel. Industry 4.0 makes the world more digital, more connected, more flexible, and more responsive. Well-known social relationships are changing beyond recognition; we are moving from business-to-consumer relationships to peer-to-peer modes (Arroyo et al., 2017).

The engineer and economist Klaus Schwab, Founder and Executive Chairman of the World Economic Forum declared during the World Economic Forum in 2016 that to the world should have a comprehensive and globally shared understanding about how the technology change dramatically our social, economic, ecological, and cultural lives. Schwab posed some questions that highlight the ways technological innovation can interact with social innovation to shape the future of our societies and benefits our societies: How will Industry 4.0 transform the healthcare sector, education, and many other industries? How we can leverage technological innovation in ways to benefit both rich and poor? How can technological innovation contribute solutions to international public health problems? How should the role of government be redefined in this technological revolution to promote transparency in economic, social, and environmental reform?

Schwab (2015) also confirms that, in the fourth industrial revolution, the social impact of technological changes on the economic sectors, labour market, production, and innovation is better understood now than during previous industrial revolutions. Meanwhile, governments and policy makers need to adapt and react quickly to the rapid evolution of the Industry 4.0 landscape by providing the enabling environment, safeguards, and policies that can guide the future for sustainable economic and social development and that harness the promise that the technologies arising from Industry 4.0 hold for people and societies.
Brynjolfsson and McAfee (2014) emphasized that, in order to take advantage of the opportunity that the new industrial revolution presents, it is important to recognize its impact on the whole society. Therefore, we have to consider social innovation alongside the technological revolution. In other words, we have to focus on the alignment between technical development (diffusion and dissemination) in one hand and the new practices required to deal with social challenges facing people and organizations on the other hand. In this view, Buhr (2017) confirms that the impact of social innovation is prominent on a system-wide level, which means that there is a mutual relationship between the technical and social innovation Technical innovations and fast technological development can positively affect the diffusion and dissemination of social innovation, and technical innovation often develops its true potential in combination with social innovation. The digitized nature of Industry 4.0 innovative products is likely to lead to both economic outcome as well as social benefits, if managed under the umbrella of sustainable development.

Industry 4.0 has huge potential to make positive impacts on our economies and societies. Uschi Schreiber, Chair of Global Accounts Committee \& Global Vice Chair of Markets at EY (Schreiber, 2017) confirmed that the multiplication of data volume available through web-connected systems accompanied by increasingly sophisticated artificial intelligence are expected to fundamentally change how society operates by providing entirely novel solutions to existing problems, including solutions and harmful systems that might not be expected. Schreiber added that Industry 4.0 introduces new possibilities or prospects for breakthroughs in healthcare, the ability to empower more people worldwide to become entrepreneurs, and increased access to education. These opportunities come about by adopting a holistic approach or enabling mechanism for Industry 4.0 in order to meet the social and environmental challenges that face societies, to mitigate or minimize unintended consequences of the rapid technological innovations, and to maximize the positive social benefits and protect public interests.

The discussion of social innovation in the context of Industry 4.0 is important to happen at early stages to address the growing concern of any possible negative externalities on individuals and society at large. This is important due to the increasing possibilities of the substitution of the human role by new technological innovations in the form of artificial intelligence, robotics, drones, virtual reality, and the IoT. As a result, certain 


\section{The Fourth Industrial Revolution (Industry 4.0): A Social Innovation Perspective}

\section{Rabeh Morrar, Husam Arman, and Saeed Mousa}

jobs may be made redundant or obsolete through automation and the digitization of production process, the qualification requirements of new jobs will be more strict, and new skills and knowledge will be required.

Industry 4.0 might lead to an unprecedented surge of technical, industrial, and social innovations, which increasingly casting doubt on the adaptive capacity of individuals and institutions with regards to threats to human identity, social stability, and economic security. As Schreiber claims, it could disrupt every industry; reshape how we work, relate, communicate, and learn; and reinvent institutions from education to transportation.

In a similar view, the growth of Industry 4.0 highlights one of the common challenges posed by the rapid growth in information and communication technology: privacy. The sharing and tracking of our information, the loss of control over our data, and the disclosure of information about our private lives are consistent with the new connectivity (Anderson \& Mattsson, 2015). For example, the revolution in biotechnology redefines what it means to be human by changing the threshold of life period, health, and cognition, which also forces us to redefine our moral and ethical boundaries (Schwab, 2015). Thus, one of the most important challenges for government, policy makers, and society is how to shift the culture of the industry and society to tackle the set of technology disruptions associated with this new industrial era. In the following section, we propose a framework to facilitate policy debates and explore innovative solutions while ensuring a sustainable future.

\section{A Framework for a Sustainable Industry 4.0}

The impact of technology has increasingly made an impact beyond industrial and economic perspectives, and it could play a critical role in speeding up the realization of a paradigm shift, as Rifkin (2014) anticipates. However, there is a need to address the various unexpected consequences of the rapid pace of technological developments. The challenges that are caused by the technological innovations need to be addressed by complementary and innovative approaches to provide innovative solutions that include radical methods that can be deployed to anticipate the future emerging technologies and their impact - from a holistic perspective.
A useful base to start with is using the sustainability concept in its totality, which exceeds the emphasis of meeting the requirements of present generations without compromising the ability of future generations. However, three key pillars - economic, social, and environmental -form the bases of our simple framework (Adam, 2006). Technological and social innovation are key drivers in providing sustainable solutions that meet the three key criteria of sustainability and can act as an assessment mechanism to any related developments of Industry 4.0, as shown in Figure 1.

Including sustainability in the framework acts as a filter and provides guidance to scrutinize technology developments coming out of Industry 4.0. It also emphasizes the reciprocal roles of technological and social innovations.

The critical success factor in such an inclusive approach is designing a creative platform. This creative platform would include experts from different disciplines including engineers, economists, social scientists, environmentalists, futurists, artist, and other creative people who can work together as part of this framework and come up with novel solutions. A specific example that could result from such an arrangement and set of competencies would be in the development of advanced and integrated simulation systems to create, for instance, a virtual environment where people and emerging technologies can interact and behave naturally. As a result, several studies can be conducted to accurately anticipate the impact of various scenarios before populating technological breakthroughs. In this example, the timely development of augmented reality and virtual reality could play a critical role if such initiatives are pursued.

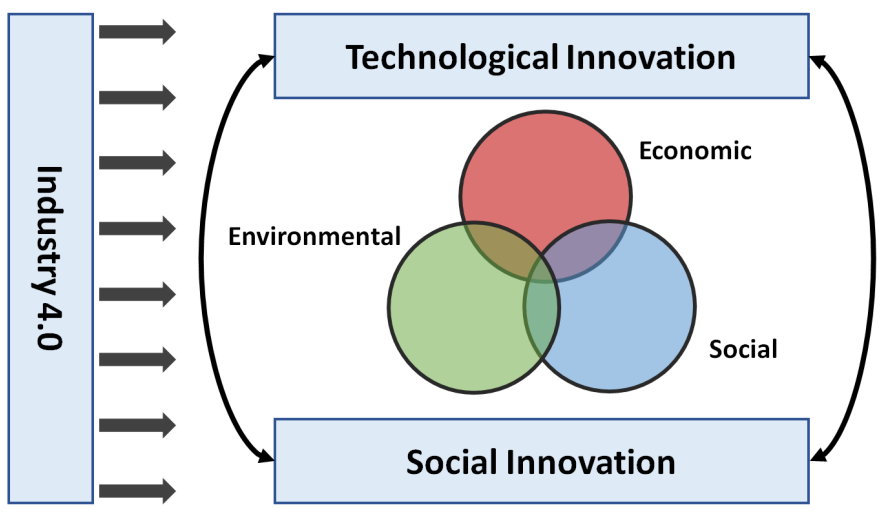

Figure 1. A framework to safeguard the potential of a sustainable Industry 4.0 


\title{
The Fourth Industrial Revolution (Industry 4.0): A Social Innovation Perspective
}

\author{
Rabeh Morrar, Husam Arman, and Saeed Mousa
}

\section{Conclusion}

This exploratory work aimed to develop an understanding of the social aspects of the Fourth Industrial Revolution by demonstrating how the interaction between technological innovation and social innovation can solve current societal and socioeconomic problems with an emphasis on sustainability. One of the most important criticisms for the previous three industrial revolutions and their associated policies is the failure to solve the most pressing issues that continue to face modern societies. These include climate change, chronic diseases, and inequality. With the transition to Industry 4.0, policy makers should think its global impact on current and potential social problems through the social dimensions of new technologies. Society at large should benefit from such industrial transformation, because consumer and producer are largely connected and both can participate in the production and consumption process.

This study confirms the importance of the duality between social and technological innovation, which can be achieved only if the Industry 4.0 is recognized simply in the form of technical and social innovation. The discussion of social innovation in the context of Industry 4.0 sheds light on the bright side of its potential instead of focusing on the potential dark side of job losses, human substitution by technological innovations, end of privacy, and potential loss of human control. The social perspective demonstrates that technical innovations are likely to positively affect the diffusion of social innovation, and vice versa. The technological revolution that accompanies the Industry 4.0 achieve its true potential in combination with social innovation. Hence, businesses that succeed in Industry 4.0 will be those that offer both social progress and economic benefits.

\section{About the Authors}

Rabeh Morrar is an Assistant Professor in Innovation Economics and Head of the Department of Economics at An-Najah National University in Nablus, Palestine. He received and $\mathrm{PhD}$ degree in Innovation Economy from Lille 1 University for Science and Technology, Lille, France. His current research interests include innovation networks, the knowledgebased economy, economic development in developing countries, the labour economy, and the service economy. Dr. Rabeh is a Fellow of the Economic Research Forum (ERF), the Turkish Economic Research Forum, the American Economic Association (AEA), the Middle East Economic Association (MEEA), and the European Association for Research in Services (RESER). He is a member of the Advisory Committee of Economic Statistics, the Palestinian Central Bureau of Statistics (PCBS), the Palestinian National Committee of Trade in Services, the National Team for Developing National Export Strategy, the Business Innovation and Partnership Centre in Palestine, the ESCWA Team for ICT and Innovation, and the National Team for Public Procurement Capacity Building Strategy. Rabeh has published more than 15 scientific papers, reports, and policy papers in different disciplines related to innovation economics, Palestinian economics, trade, and the service economy.

Husam Arman is an Associate Research Specialist at the Kuwait Institute for Scientific Research. Dr. Arman is currently engaged in work related to competitiveness and innovation and SME development. He studies and works in the leading edge subjects of strategic technological innovation and $R \& D$ management. During his Research Fellow posting and PhD studies at The University of Nottingham, United Kingdom, he developed methodologies to optimize technology investments strategies within large firms such as Rolls-Royce. He has worked for more than five years in universities in teaching and research. His work has appeared in the International Journal of Innovation and Technology Management, $R \& D$ Management Journal, the International Journal of Industrial and Systems Engineering, the International Journal of Technology Intelligence, and Clean Technologies and Environmental Policy, and he has presented at conferences such as PICMET and IAMOT.

Continued on next page... 


\section{The Fourth Industrial Revolution (Industry 4.0): A Social Innovation Perspective}

\section{Rabeh Morrar, Husam Arman, and Saeed Mousa}

\section{About the Authors (continued)}

Saeed Mousa is a Lecturer in Innovation and Entrepreneurship at the Palestinian Technical University Kadoorie (PTUK), where he teaches Innovation, Technology and business related courses. In addition, is Head of the Studies \& Development Division at PTUK, where he conducts research regarding improving the university, such as strategic and implementation planning through preparing and submitting development proposals, as he is responsible for developing and driving innovation roadmap through encouraging creativity in $R \& D$ team. He holds a master's degree in Innovation Economics from Friedrich Schiller University in Germany. Saeed's current research interests span a wide range of topics regarding innovation, such as social innovation, technology innovation, and non-technical innovation.

\section{References}

Abbott, D. 2014. Applied Predictive Analytics: Principles and Techniques for the Professional Data Analyst. Hoboken, NJ: John Wiley.

Adams, W. M. 2006. The Future of Sustainability: Re-Thinking Environment and Development in the Twenty-First Century. Report of the IUCN Renowned Thinkers Meeting. Gland, Switzerland: The World Conservation Union (IUCN).

Almada-Lobo, F. 2016. The Industry 4.0 Revolution and the Future of Manufacturing Execution Systems (MES). Journal of Innovation Management, 3(4): 16-21.

Andersson, P., \& Mattsson, G. L. 2015. Service Innovations Enabled by the Internet of Things. IMP Journal, 9(1): 85-106.

http://doi.org/10.1108/IMP-01-2015-0002

Arroyo, L., Murillo, D., \& Val, E. 2017. Trustful and Trustworthy: Manufacturing Trust in the Digital Era. Barcelona: ESADE Roman Llull University Institute for Social Innovation; EY Fundación Espana.

Bauer, H., Patel, M., \& Veira, J. 2014. The Internet of Things: Sizing up the Opportunity (Technical Report). McKinsey Insights, December 2014. Accessed November 1, 2017:

http://www.mckinsey.com/insights/high_tech_telecoms_internet/ the_internet_of_things_sizing_up_the_opportunity

Brynjolfsson, E., \& McAfee, A. 2014. The Second Machine Age: Work Progress, and Prosperity in a Time of Brilliant Technologies. New York: W. W. Norton \& Company.

Brocklesby, M. A., \& Fisher, E. 2003. Community Development in Sustainable Livelihoods Approaches - An Introduction. Community Development Journal, 38(3): 185-198. https://doi.org/10.1093/cdj/38.3.185
Buhr, D. 2015. Social Innovation Policy for Industry 4.0. Tübingen, Germany: Eberhard Karls University of Tübingen.

Carr, N. 2003. IT Doesn't Matter. Harvard Business Review, 81(5): 41-49.

Cordes, F., \& Stacey, N. 2017. Is UK Industry Ready for the Fourth Industrial Revolution? Boston, MA: The Boston Consulting Group.

Da Silveira, G., Borenstein, D., \& Fogliatto, F. S. 2001. Mass Customization: Literature Review and Research Directions. International Journal of Production Economics, 72(1): 1-13. https://doi.org/10.1016/S0925-5273(00)00079-7

Drucker, P. 2014. Innovation and Entrepreneurship. New York: Routledge.

Dutton, H. W. 2014. Putting Things to Work: Social and Policy Challenges for the Internet of Things. Info, 16(3): 1-21. https://doi.org/10.1108/info-09-2013-0047

Gallouj, F., Weber, M., Metka, S., \& Rubalcaba, L. 2014. The Futures of the Service Economy in Europe: A Foresight Analysis. Technological Forecasting \& Social Change, 94: 80-96. https://doi.org/10.1016/j.techfore.2014.06.009

Friess, P., \& Ibanez, F. 2014. Putting the Internet of Things Forward to the Next Level. In O. Vermesan \& P. Friess (Eds.), Internet of Things Applications - From Research and Innovation to Market Deployment: 3-6. Gistrup, Denmark: Rivers Publishers.

Geiger, R., \& Sá, C. 2013. Tapping the Riches of Science: Universities and the Promise of Economic Growth. Cambridge, MA: Harvard.

Goldenberg, B. 2015. The Definitive Guide to Social CRM: Maximizing Customer Relationships with Social Media to Gain Market Insights, Customers, and Profits. Upper Saddle River, NJ: Pearson Education.

Hahn, J., \& Andor, L. 2013. Guide to Social Innovation. Brussels: European Commission.

Jacobsen, J. 2011. Sustainable Business and Industry: Designing and Operating for Social and Environmental Responsibility. Milwaukee, WI: ASQ Quality Press.

Lee, J., Kao, H.-A., \& Yang, S. 2014. Service Innovation and Smart Analytics for Industry 4.0 and Big Data Environment. Procedia CIRP, 16: 3-8. https://doi.org/10.1016/j.procir.2014.02.001

Kagermann, H., \& Wahlster, W. 2014. Recommendations for Implementing the Strategic Initiative INDUSTRIE 4.0: Final Report of the Industrie 4.0 Working Group. Munich: National Academy for Science and Engineering.

Luppicini, R. 2012. Ethical Impact of Technological Advancements and Applications in Society. Hershey, PA: Information Science Reference.

Marolt, M., Pucihar, A., \& Zimmermann, D. H. 2015. Social CRM Adoption and Its Impact on Performance Outcomes: A Literature Review. Organizacija, 48(4): 260-271. http://doi.org/10.1515/orga-2015-0022

Morelli, N. 2007. Social Innovation and New Industrial Contexts: Can Designers "Industrialize" Socially Responsible Solutions? Design Issues, 23(4): 12-15. http://dx.doi.org/10.1162/desi.2007.23.4.3

Moss Kanter, R., \& Litow, S. S. 2009. Informed and Interconnected: A Manifesto for Smarter Cities. Harvard Business School Working Paper 09-141. Boston, MA: Harvard Business School 


\section{The Fourth Industrial Revolution (Industry 4.0): A Social Innovation Perspective Rabeh Morrar, Husam Arman, and Saeed Mousa}

Mulgan, G. 2006. The Process of Social Innovation. Innovations: Technology, Governance, Globalization, 1(2): 145-162. http://dx.doi.org/10.1162/itgg.2006.1.2.145

Mulgan, G., Tucker, S., Ali, R., \& Sanders, B. 2007. Social Innovation: What It Is, Why It Matters and How It Can Be Accelerated? Oxford: Skoll Centre for Social Entrepreneurship, Oxford SAID Business School.

Murray, R., Caulier-Grice, J., \& Mulgan, G. 2010. The Open Book of Social Innovation. London: National Endowment for Science, Technology and the Art.

Pascall, T. 2017. Innovation and Industry 4.0. Disruption, April 19, 2017. Accessed November 1, 2017: https://disruptionhub.com/innovation-industry-4-0/

Phills, J. A. Jr., Deiglmeier, K., \& Miller, D. T. 2008. Rediscovering Social Innovation. Stanford Social Innovation Review, 6(4): 34-43.

PwC. 2017. Industry 4.0: The Current State of Play in Flemish Manufacturing. Press Release. PwC, March 31, 2017. Accessed November 1, 2017: https://www.pwc.be/en/news-publications/press/2017/industry4-0-the-current-state-of-play-in-flemish-manufacturing.html

Rifkin, J. 2014. The Zero Marginal Cost Society: The Internet of Things, the Collaborative Commons, and the Eclipse of Capitalism. New York: St. Martin's Press.

Schmitt, K. 2017. Top 5 Reasons Why Industry 4.0 Is Real And Important. Digitalist Magazine, October 15, 2013. Accessed July 26, 2017:

https://www.digitalistmag.com/industries/manufacturingindustries/2013/10/15/top-5-reasons-industry-4-0-realimportant-0833970
Schreiber, U. 2017. EY Women. Fast Forward. An Interview with Uschi Schreiber. Leaders, 39(1): 40.

Schwab, K. 2015. The Fourth Industrial Revolution. Geneva: World Economic Forum.

Seyfang, G., \& Haxeltine, A. 2012. Growing Grassroots Innovations: Exploring the Role of Community-Based Initiatives in Governing Sustainable Energy Transitions. Environment and Planning C: Politics and Space, 30(3): 381-400. http://doi.org/10.1068/c10222

Seyfang, G., Park, J. J., \& Smith, A. 2013. A Thousand Flowers Blooming? An Examination of Community Energy in the UK. Energy Policy, 61: 977-989. https://doi.org/10.1016/j.enpol.2013.06.030

Vermesan, O., Friess, P., Guilleman, P., Gusmeroli, S., Sundmaeker, H., Bassi, A., Jubert, I. S., Mazura, M., Harrison, M., Eisenhauer, M., \& Doody, P. 2009. Internet of Things - Strategic Research Roadmap. Brussels: European Commission, Information Society and Media DG; Cluster of the European Research Projects on the Internet of Things (CERP-IoT).

http://hdl.handle.net/11250/2430372

Vermesan, O., Friess, P., Guillemin, P., \& Sundmaeker, H. 2014. Internet of Things Strategic Research and Innovation Agenda. In O. Vermesan \& P. Friess (Eds.), Internet of Things Applications From Research and Innovation to Market Deployment: 7-142. Gistrup, Denmark: Rivers Publishers.

Waters, R. 2016. Artificial Intelligence: Can Watson Save IBM? Financial Times, January 5, 2016. Accessed November 1, 2017: https://www.ft.com/content/dced8150-b300-11e5-83589a82b43f6b2f 


\section{Academic Affiliations and Funding Acknowledgements}

Canadà
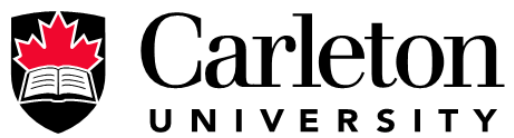

U N I V E R S I T Y

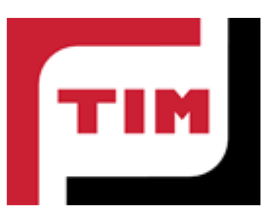

The Federal Economic Development Agency for Southern Ontario (FedDev Ontario; feddevontario.gc.ca) is part of the Innovation, Science and Economic Development portfolio and one of six regional development agencies, each of which helps to address key economic challenges by providing regionallytailored programs, services, knowledge and expertise.

- The TIM Review receives partial funding from FedDev Ontario's Investing in Regional Diversification initiative.

Technology Innovation Management (TIM; timprogram.ca) is an international master's level program at Carleton University in Ottawa, Canada. It leads to a Master of Applied Science (M.A.Sc.) degree, a Master of Engineering (M.Eng.) degree, or a Master of Entrepreneurship (M.Ent.) degree. The objective of this program is to train aspiring entrepreneurs on creating wealth at the early stages of company or opportunity lifecycles.

- The TIM Review is published in association with and receives partial funding from the TIM program. 